\title{
KOALISI MASYARAKAT LOKAL PRIBUMI GUGAT AMNT : ANALISIS WACANA KRITIS
}

\author{
Eka Haryanti \\ Program Studi Teknik Informatika Universitas Teknologi Sumbawa \\ ekaharyanti.uts@gmail.com
}

\begin{tabular}{ll}
\hline \multirow{2}{*}{$\begin{array}{l}\text { Diterima: } \\
\text { Bulan Januari }\end{array}$} & Abstrak \\
\cline { 2 - 3 } 2020 & Setiap pilihan makna dimotivasi secara ideologis. Ideologi paling efektif bila \\
& pekerjaannya tidak terlihat. Menafsirkan ideologi dalam teks dapat dilihat dari pilihan \\
& kosakata dan konstruksi gramatikalnya. Untuk menganalisisnya kita perlu menafsirkan \\
& tidak hanya teks tapi juga hubungan antara teks, dan kondisi sosialnya. Menurut \\
Diterbitkan: & Fairclough, mereka bisa dikelompokkan dalam tiga tahap, yaitu deskripsi, interpretasi dan \\
Bulan Februari & penjelasan. Tahapan deskripsi berkaitan dengan sifat formal teks, interpretasi berkaitan \\
2020 & dengan hubungan antara teks dan interaksinya, penjelasan berkaitan dengan hubungan \\
& antara interpretasi dan konteks sosial. \\
Keyword: & Untuk menganalisis data menggunakan metode referensial, metode substitusi dan metode \\
Analisis Wacana & inferensi abduktif. Metode referensial adalah menganalisa sistem penilaian dan \\
Kritis (CDA), & diskursivitas intertekstualitas teks. Untuk melakukan analisis terhadap sistem penilaian \\
Mikro, Meso, & yang valid diperlukan metode substitusi. Kemudian metode inferensi abduktif diperlukan \\
Makro & untuk menganalisis keterkaitan antar teks. \\
& Dari hasil analisis data, dapat disimpulkan bahwa setiap media memiliki caranya \\
& tersendiri untuk mengemukakan ideologinya. Ideologi telah menutup hubungan dengan \\
& target pasar yaitu pembaca. Rungan Samawa adalah suatu wadah online masyarakat \\
& Sumbawa, berita yang sangat gamblang dan singkat, dengan pilihan kosa kata yang tajam, \\
& semuanya terkait dengan genre berita yang dimilikinya. Kasus Koalisi Masyarakat Lokal \\
& Pribumi Gugat Amnt merupakan bentuk dari kepedulian masyarakat Samawa yang \\
& berada di seluruh penjuru dunia.
\end{tabular}

\section{PENDAHULUAN}

Bahasa merupakan media bagi manusia dalam berkomunikasi. Melalui bahasa, manusia dapat mengungkapkan ide, pikiran, dan perasaannya. Namun demikian, saat ini definisi bahasa telah berkembang sesuai fungsinya bukan hanya sebagai alat berkomunikasi. Saat ini, bahasa telah menjadi media perantara dalam pelaksanaan kuasa melalui ideologi. Bahkan bahasa juga menyumbang proses dominasi terhadap orang lain oleh pihak lain (Fairclough, 1989:2). Sejalan dengan pernyataan di atas, Halliday (1978:2) juga menegaskan bahwa sesungguhnya bahasa bukan hanya terdiri atas kalimat, melainkan juga terdiri atas teks atau wacana yang di dalamnya terdapat tukar-menukar maksud dalam konteks interpersonal antara satu dengan yang lain. Konteks dalam tukar menukar maksud itu tidak bersifat kosong dari nilai sosial, tetapi sangat dipengaruhi oleh konteks sosial budaya masyarakatnya.

Salah satu bidang yang juga memanfaatkan bahasa dalam kaitannya dengan pelaksanaan kuasa dalam ideologi seperti yang dijelaskan di atas adalah bidang media. Sebagian besar bentuk produksi media diwujudkan dalam bentuk bahasa. Dengan demikian, hubungan antara bahasa dan media merupakan dua hal yang tidak dapat dipisahkan. Richardson (2007: 6) menyatakan bahwa "the language used in newspaper is one key site in naturalisasion of inqequality and neutralisasion of dissert". Pemanfaatan bahasa yang saat ini mendominasi media adalah penggunaan bahasa dalam wacana politik. Wacana politik banyak dihasilkan oleh media seiring dengan situasi politik Indonesia yang sangat dinamis.

Wacana merupakan hasil konstruksi pihak yang memiliki kekuasaan (power). Wacana dibangun untuk menghasilkan suatu kebenaran yang dikonstruksi oleh pihak pemegang kekuasaan. Oleh karena itu tidak mengherankan jika satu wacana yang sama direpresentasikan secara berbeda oleh pemegang kekuasaan / rezim pemerintahan yang berbeda karena setiap rezim pasti memproduksi kebenarannya sendiri untuk memapankan kekuasaannya. Inilah yang oleh Foucault disebut sebagai regime of truth. Dalam memproduksi kebenarannya tersebut, tata alur sebuah wacana disusun sedemikian rupa sehingga dapat mengatur bagaimana sebuah wacana harus dibaca dan dimengerti. Karena sebuah wacana sangat mungkin direpresentasikan secara berbeda, maka pendefinisian benar atau salah atas sebuah wacana yang samapun akan berbeda. Semua disesuaikan pada kepentingan pihak pemegang kuasa. Itu artinya, kebenaran yang terkandung dalam sebuah wacana bukanlah sesuatu yang alami. Sebaliknya, kebenaran tersebut merupakan hasil konstruksi yang 
diproduksi dengan cara sedemikian rupa sehingga masyarakat meyakininya sebagai sebuah kebenaran dan bahkan hidup di dalamnya.

Setiap media memiliki ideologi dalam pemberitaan. Menurut Eriyanto (2000) ideologi sebuah media dapat diamati melalui pilihan bahasa serta struktur gramatika yang digunakan memiliki ideologi yang sama, begitu juga pada media pamphlet. Diharapkan berita yang diturunkan oleh media tersebut dapat diterima secara "taken for granted" oleh pembacanya. Tulisan ini berusaha untuk mengidentifikasi ideologi media yang diwakili oleh sebuah pamplet berita "Koalisi Masyarakat Lokal Pribumi Gugat Amnt”. Untuk menganalisis wacana yang ada di dalam pamphlet, menggunakan studi analisis wacana kritis (CDA), yaitu sebuah studi yang tidak hanya menganalisis pemakaian bahasa dalam tuturan dan lisan tetapi melihat bahasa sebagai praktik sosial. Eriyanto (2000: 7) mengatakan pengkaitan ini menyebabkan terjadinya hubungan dialektis antara wacana dengan situasi, institusi serta struktur sosial yang membentuk wacana tersebut.

Analisis teori yang digunakan dalam tulisan ini adalah analisis wacana pendekatan Norman Fairclough (1992b, 1995a; 1998; 2000) yang dikenal dengan nama analisis wacana tiga dimensi. Yang dimaksud dengan analisis wacana tiga dimensi ini ialah analisis yang melibatkan tiga tingkat analisis: (1) analisis teks atau textual (mikro), yaitu pendeskripsian (description) mengenai teks; (2) analisis wacana atau discourse practice (meso), yaitu interpretasi (interpretation); (3) analisis sosio-budaya atau sociocultural practice (makro), yaitu penjelasan (explanation) (Fairclough, 1992a:73; 1995a:59; Idris, 2006:75).

Sumber wacana yang dianalisis berasal dari Rungan Samawa pada tanggal 1 November 2017, yang berjudul "Koalisi Masyarakat Lokal Pribumi Gugat Amnt". Sumber yang dianalisis dipilih karena memiliki muatan muatan teks yang mengandung representasi yang penting untuk dianalisis secara kritis. Tujuan tulisan secara umum adalah untuk mengidentifikasi serta menjelaskan ideologi teks pada pamphlet "Koalisi Masyarakat Lokal Pribumi Gugat Amnt" melalui tahapan analisis wacana kritis model Fairclough.

\section{PEMBAHASAN}

\section{Analisis Teks atau Textual (Mikro) Pamphlet "Koalisi Masyarakat Lokal Pribumi Gugat Amnt"}

Dari berbagai alat kebahasaan yang digunakan media Indonesia dalam pemberitaan "Koalisis
Masyarakat Lokal Pribumi Gugat Amnt", terdapat dua alat yang menandai representasi tema yang terlibat dalam pemberitaan tersebut. Yaitu melalui diksi, dan penggunaan kalimat luas sebab akibat. Penggunaan diksi "lokal pribumi" yang lebih mendominasi dibandingkan dengan diksi lokal telah menandai bahwa Rungan Samawa lebih menempatkan tindakan koalisis masyarakat lokal pribumi gugat Amnt tersebut sebagai suatu "gerakan massa" yang terjadi di Nusa tenggara Barat. Sementara itu, pemanfaatan kalimat luas dengan konstruksi sebab akibat telah menempatkan Amnt dalam representasi yang negatif karena diposisikan sebagai pihak yang menjadi penyebab terjadinya aksi gerakan tersebut. Rungan Samawa lebih dominan menyuarakan pendapat dari pihak yang berpihak kepada masyarakat daripada menyuarakan pendapat yang memihak kepada Amnt. Hal ini menempatkan pribumi pada representasi yang positif dan Amnt pada representasi yang negatif. Di bawah ini adalah analisis dari aspek kebahasaan tersebut.

\section{(1) Koalisi masyarakat lokal pribumi gugat Amnt}

(2) Lokal pribumi wajib masuk dalam jajaran direksi Amnt,

(3) Hentikan semua upaya pembungkaman kepada masyarakat lokal pribumi.

Contoh data (1-3) menandai bahwa untuk kasus dalam konteks yang sama, Rungan Samawa memilih diksi yang bermacam-macam, yaitu diksi koalisi masyarakat lokal pribumi yang menggugat Amnt, lokal pribumi masuk jajaran direksi Amnt, dan hentikan semua upaya pembungkaman kepada masyarakat lokal pribumi. Ketiga diksi tersebut memiliki makna semantik yang berlainan pula. Secara sematik leksikal, makna kata lokal pribumi yang berarti 'penghuni asli yang berasal dari suatu tempat/daerah yang bersangkutan ' memiliki makna yang lebih netral dibandingkan gerakan masyarakat setempat menuntut Amnt yang memiliki makna 'gerakan pemboikotan masyarakat setempat'.

\section{(4) Komando Pasukan Lapangan,}

\section{(5) Tiga tuntutan KMLP,}

(6) Mendesak agar rekrutmen pekerja terbuka dan jangan ada upaya menutupi ke publik luas,

Contoh data (4-6) menandai bahwa untuk kasus dalam konteks terdiri dari diksi komando 
pasukan lapangan, tiga tuntutan KMLP, dan mendesak agar rekrutmen pekerja terbuka dan jangan ada upaya menutupi ke publik luas. Ketiga diksi tersebut memiliki makna semantik yang berlainan pula. Secara sematik leksikal, makna kata komando pasukan yang berarti 'aba-aba atau perintah pasukan inti yang menjadi pokok dalam gerakan perang' memiliki makna yang lebih netral dibandingkan gerakan masyarakat setempat menuntut Amnt yang memiliki makna 'pasukan khusus yang dipersiapkan untuk gerakan pemboikotan atas Amnt'.

\section{Analisis Wacana atau Discourse Practice (Meso) Pamphlet "Koalisis Masyarakat Lokal Pribumi Gugat Amnt"}

AMNT merupakan perusahaan tambang yang berlokasi di wilayah Kabupaten Sumbawa Barat. PT. Amman Mineral Nusa Tenggara (AMNT) merekrut tenaga kerja dari luar. Macmahon adalah mitra perusahaan yang kini dilaporkan mengelola aktifitas tambang, manpower dan pengolahan serta pemurnian bahan tambang menyatakan membutuhkan tenaga kerja selama setahun kedepan untuk memenuhi selama satu tahun kedepan untuk memenuhi job skill dan non skill diperusahann itu. Iklim investasi di daerah ini akan kondusif dan aman apabila disetarakan oleh rekrutmen yang seimbang.

Semua investor yang menanamkan modalnya di Sumbawa Barat, khususnya investor pertambangan dapat berkembang dengan baik, karena pemerintah daerah memberikan jaminan keamanan, itulah sebabnya perusahaan merekrut tenaga dari luar. Namun tenaga kerja yang berada di dalam Sumbawa banyak yang belum terpanggil dan mengakibatkan ketidak setaraan terhadap penduduk lokal dengan penduduk pendatang.

Koalisi Masyarakat Lokal Pribumi menggugat Amnt dengan tiga tuntutan, yaitu (1) "lokal pribumi wajib masuk dalam jajaran direksi Amnt”, hal ini ditafsirkan bahwa masyarakat lokal juga membutuhkan lapangan pekerjaan di perusahaan Amnt sesuai dengan jenjang pendidikan dan keahlian masyarakat tersebut; (2) "mendesak agar rekrutmen pekerjaan terbuka dan jangan ada upaya menutupi ke publik luas", hal ini juga ditafsirkan bahwa perekrutan tidak berkesan ditutup-tutupi pada pihak lokal, namun saling bekerja sama ada keadaan bias kondusif; (3) "hentikan semua upaya pembungkaman kepada masyarakat lokal PRIBUMI”, ini ditafsirkan bahwa segala bentuk kolusi dan nepotisme kepada pihakpihak terkait pribumi untuk segera dihentikan, dikarenakan oleh adanya bentuk dari sifat negative itulah perusahaan bias semena-mena dalam perekrutan tenaga kerja dari luar.

\section{Analisis Sosio-budaya atau Sociocultulral practice (Makro) Pamphlet "Koalisi Masyarakat Lokal Pribumi Gugat Amnt"}

Situasi sosial politik dan budaya yang terjadi saat pemberitaan "Koalisi Masyarakat Lokal Pribumi Gugat Amnt" ini juga tidak dapat dilepaskan konteks yang membangun pemberitaan tersebut. Dapat diketahui bersama bahwa perusahaan tambang emas yang berada di daerah Sumbawa Barat merupakan perusahaan yang dulunya dikelola oleh pihak asing, yang kemudia jual kembali kepada perusahaan dalam negeri. Banyak tenaga kerja yang direkrut dari luar Negara dan luar provinsi Nusa Tenggara Barat, Dengan adanya perekrutan yang lebih mendominasi pada tenaga kerja dari luar provinsi, menjadi kesenjangan yang terjadi pada masyarakat lokal ataupun masyarakat setempat. Seluruh peristiwa tersebut mendapat pemberitaan Rungan Samawa.

Atas bentuk protes yang dilakukan oleh masyarakat lokal pribumi terhadap PT Amnt, mendapat respon yang positif dari pihak Pemerintah Daerah dalam hal ini Bupati KSB dan Departemen Tenaga Kerja. Warga lokal yang tidak memiliki pekerjaan tidak terfasilitasi, kalau di dalam perusahaan itu masih ada kesempatan dan peluang lapangan kerja untuk warga pribumi. Keberadaan PT.AMNT dan PT. McMahon di Sumbawa Barat itu memberikan kontribusi besar bagi Pendapatan Asli Daerah (PAD) dan pertumbuhan ekonomi masyarakat. Pekerja local atau witinglist akan direkrut tetap dengan syarat formal, seperti lamaran dan serangkaian tes interview. Para Waiting List tersebut dijamin untuk bekerja dan menjadi skala prioritas, tidak sama proses perekritan dengan kebutuhan tenaga kerja yang baru dibuka. Khusus witing list pendaftaran lamaran bias disampaikan langsung ke secretariat tim rektrutmen satu pintu, sementara pelamar umum disampaiakan melalui kantor post.

\section{SIMPULAN}

Hasil tulisan ini menunjukkan bahwa aspek kebahasaan diksi, penggunaan kalimat, dan pemilihan sumber yang digunakan Rungan Samawa telah menempatkan tema pemberitaan sebagai sebuah gerakan masyarakat, selain itu aspek kebahasaan juga telah mendapatkan respon dari pihak perusahaan Amnt dalam representasi yang negatif. Hal ini erat kaitannya dengan ideologi nasionalisme yang dianut oleh institusi Rungan Samawa dan Pemerintah Daerah serta Departemen Tenaga Kerja yang lebih membela gerakan masyarakat lokal 
melalui tuntutan yang diajukan oleh masyarakat lokal.

\section{DAFTAR PUSTAKA}

Eriyanto. 2000. Analisis Wacana. Malang: LkiS.

Fairclough, Norman. 1989. Language and Power. London: Longman.

Fairclough, Norman. 1992a. Discourse and Social Change. Cambridge: Polity Press.

Fairclough, Norman. 1992b. Discourse and Text: Linguistic and Intertextual Analysis. Cambridge: Polity Press.

Fairclough, Norman. 1995a. Media Discourse. London: Edward Arnold.

Fairclough, Norman. 1995b. Critical Discourse Analysis: The Critical Study of Language. London: Longman.

Fairclough, Norman. 1998. "Political Discourse in The Media: An Analytical Framework", dalam

Allan Bell and Peter Garret (editor). Approaches to Media, hlm. 142-162. Massachusetts: Blackwell Publisher Inc.

Fairclough, Norman. 2000. "Critical Analysis of Media Discourse", dalam Paul Marris and Sue

Thornham (editor). Media Studies a Reader, hlm. 308-328. Washington New York University Press.

Halliday, M. A. K. 1978. Language as Social Semiotic. London: Edward Arnold.

Idris Aman. 2006. Bahasa dan Kepemimpinan Analisis Wacana Mahathir Mohammad. Bangi:

Penerbit Universiti Kebangsaan Malaysia.

Richardson. 2007. Analysing Newspaper: An Approach from Critical Discourse Analysis. England: Paldrave Macmillan.

\section{LAMPIRAN}

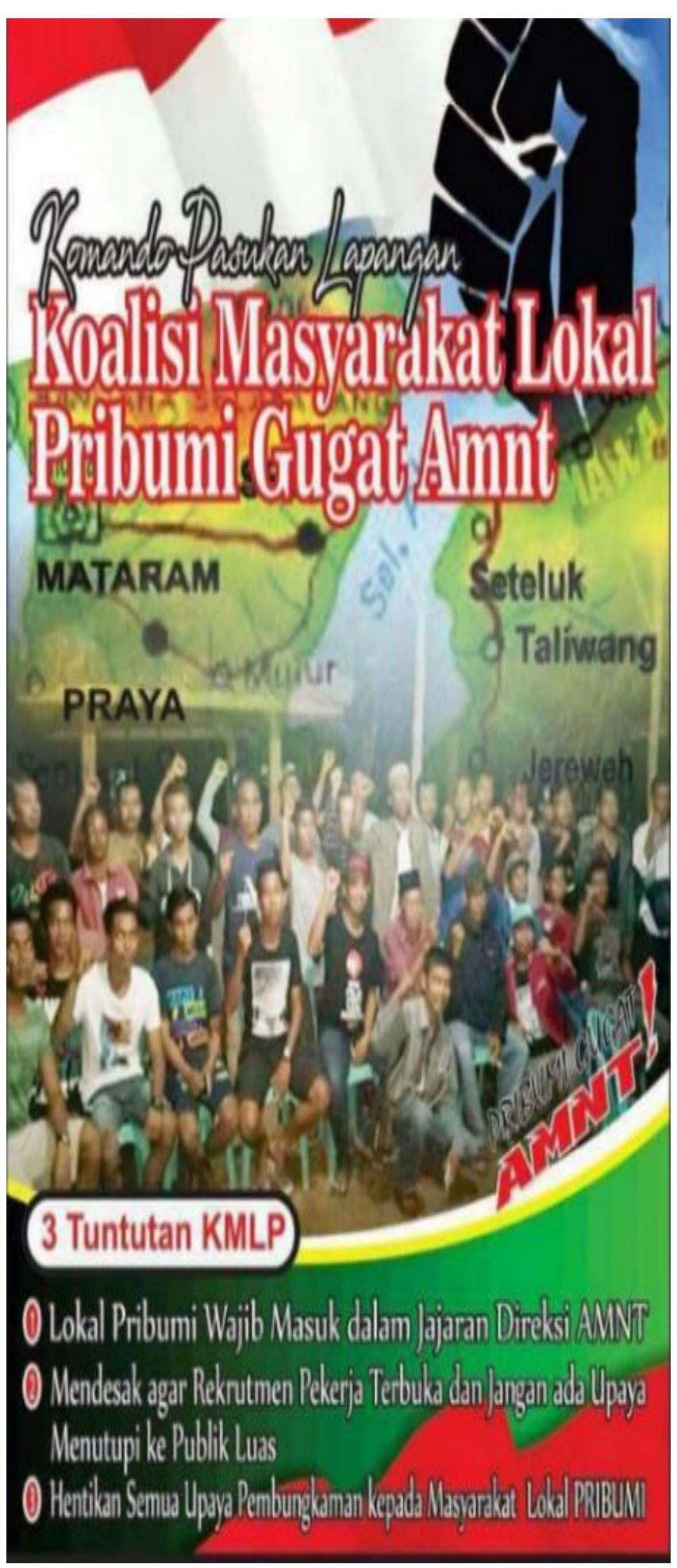

